Original article

\title{
Burden of comorbidities among diabetic patients in Latur, India
}

\author{
Balasaheb Bansode ${ }^{\mathrm{a}, *}$, Jang Bahadur Prasad ${ }^{\mathrm{b}}$

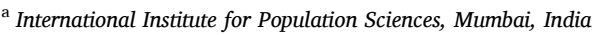 \\ ${ }^{\mathrm{b}}$ Department of Epidemiology and Biostatistics, KLE University, Belgaum, 590010, Karnataka, India
}

\section{A R T I C L E I N F O}

\section{Keywords:}

Blood pressure

Cardiovascular diseases

Retinopathy

Rheumatism

\begin{abstract}
A B S T R A C T
Background: Diabetes ailment is a route of the multi-morbidity's ailments. In Maharashtra state, Latur district have a higher proportion of diabetics. According to DLHS-4 (2012-013) and NFHS-4 (2015-016) blood sugar $>140 \mathrm{mg} / \mathrm{dl}$ is around $14 \%$ and $17 \%$ respectively in Latur. Hence, study was undertaken to find out the burden of comorbidities among diabetes persons and its determinants.

Materials and methods: This study used house listing method for self-reported diabetic person. Multistage stratified sampling technique was used to collect data. Two sub-divisions have selected in Latur districts. Three villages and three CEB randomly selected based on prevalence of diabetes among social strata in each subdivision of Latur. Furthermore, data was collected from 505 self-reported diabetic patients of 413 household during May to October 2017 and analysed by bivariate and multivariate techniques.

Results: The prevalence of major comorbidities was blood pressure (28.5\%), cardiovascular diseases (19.5\%), retinopathy $(21.8 \%)$ and rheumatism $(24.4 \%)$. Health risk factors were blood sugar level, overweight, substance use and non-exercised, which shown more likely to develop the morbidities among diabetic patients.

Conclusions: Increase of number of comorbidities in diabetic patients indicates lack of awareness of causes and consequences of diabetes. Hence, there is needs awareness program about diabetes prevention and management through health education, disease management programmes, trained peers, community health workers and community-based programmes.
\end{abstract}

\section{Introduction}

Epidemiologically, diabetes is a major non-communicable disease (NCD). Over the years, its prevalence has increased and widened to affect all socio-demographic segments of the population. ${ }^{1}$ Rapid economic development and urbanization, ${ }^{2}$ lifestyle changes, ${ }^{3}$ increasing obesity levels ${ }^{4}$ and reduced physical inactivity of people in Asian countries, particularly in India. It has led to a shift in health problems from communicable to non-communicable diseases (Gupta et al., 2012).

Among NCDs, diabetes has emerged as one of the major causes of illness and premature deaths around the world. ${ }^{5}$ Incidences of diabetes are growing in the present 21 st century. ${ }^{6}$ The number of adults with diabetes in the world has increased from 108 million in 1980 to an estimated 422 million in 2014 (NCD Risk Factor Collaboration, 2016).

The largest proportion increase in new cases of diabetes has occurred in East Asia and South Asia. The two regions have respectively 106 million and 86 million diabetics (NCD Risk Factor Collaboration, 2016). India has the second largest population of diabetics in the world, next to the China. ${ }^{7}$ Diabetes is an iceberg ailment: it can remain undetected for a long time during which its adverse effects spread to various organs of the body. The diabetes epidemic has engulfed all demographic and socio-economic sections. Experts have warned that the spread of diabetes could have long lasting negative impact on the health of the people, as well as the overall economic wellbeing of the nation., 6,7

There are several risk factors of diabetes, which can be classified into modifiable and non-modifiable risk factors. Modifiable factors include obesity, sedentary lifestyles, improper diet, stress, alcohol and viral infections. ${ }^{5,7-9}$ Non-modifiable risk factors include socioeconomic status, genetic predisposition to the disease and family history. ${ }^{10,11}$ The proportion of diabetic patients with multiple morbidities is rising and the problem of lack of health care facilities cannot be ignored. ${ }^{12}$ Approximately one third to a half of diabetic patients are living with one or more types of morbidities. ${ }^{13}$ According to DLHS-4 factsheet (2012-13), in Latur, $14 \%$ of the population reported blood sugar level $>140 \mathrm{mg} / \mathrm{Id}$. In the NFHS-4 factsheet (2015-16), this figure had increased to $17 \%$. This is a significant increase and hence, this study has

\footnotetext{
* Corresponding author.

E-mail addresses: bansodebalasaheb7@gmail.com (B. Bansode), jbiips12@gmail.com (J.B. Prasad).
} 
taken into account to highlight the burden of comorbidities among diabetes in Latur along with its symptoms and their socio-demographic, economic and health determinants.

\section{Materials and methods}

The study was conducted in Latur district of Maharashtra state. The selection of Latur was determined because of the higher (third rank) prevalence of diabetes in the district of Maharashtra (DLHS-4, 2012-13).

\subsection{The study area}

Latur district is situated in the South-East of Maharashtra on the border of Maharashtra and Karnataka. The district is divided into two administrative sub-divisions (Latur and Udgir) and ten tehsils. Latur subdivision includes Latur and Ausa tehsils, while the Udgir comprises Udgir, Ahmadpur, Nilanga, Chakur, Renapur, Deoni, Jalkot and ShirurAnantpal tahsils. The urban population of Latur in 2011 was $25.5 \%$ of the district. Latur district's literacy rate was $77.3 \%$ in 2011 . District's economy is mainly depending on agriculture with $71.5 \%$ of the workforce engaged in the primary sector (Census 2011). Furthermore, the population of Latur district is $24,56,885(18,28,170$ in rural areas and 628,714 in urban). There are 46 Primary Health Centres (PHC's) and 252 sub-centres in the rural parts of Latur District. Each PHC on an average caters to a population of about 30,000 people, while each subcentre caters to 5,000. In addition, Latur district consist of ten rural and two sub-district hospitals (zplatur.gov.in/htmldocs/health/AboutDeparetment.html, accessed on 22 July 2016).

\subsection{Estimation of sample size}

The sample selected for study consisted of respondents, reported diabetic condition. The estimated required sample was based on proportion of diabetics in the district. (According to DLHS-4 factsheet for Latur, $14 \%$ of the population aged 18 years and above reported blood sugar levels $>140 \mathrm{mg} / \mathrm{dl}$, which is high) (DLHS-4, 2012-13). The required sample size at $95 \%$ confidence interval, $4 \%$ margin of error, 1.5 design effects and $10 \%$ non-response rate was estimated as 497 . However, study was carried out on 505 persons.

\subsection{Sample design}

A sample of 505 self-reported diabetic patients from 413 household were chosen using a multistage stratified sampling technique. One tehsil was selected from each sub-division of Latur district. From Latur subdivision, Latur tehsil was selected because it is the headquarters and has relatively better healthcare facilities. From the Udgir sub-division, Nilanga tehsil was randomly chosen. From each of the selected tehsils (Latur and Nilanga), three villages and three census enumeration blocks (CEBs) were selected based on the proportion of population size (PPS).

\subsection{Data collection}

The selection of villages and CEBs were completed based on 2011 census information. Further, number of current households at the time survey was not possible from the census 2011. Hence, authors themself visited all-selected villages and CEB, and done the house listing for further sampling. A complete house listing was obtained for identifying adults aged 18 and higher with diabetes in household. With this approach, 42 self-reported diabetics based on medical records from each $\mathrm{CEB} /$ village were selected randomly for the study. In all, 6 CEBs and 6 villages were selected from the two tehsils. Data were collected during May 15 to November 15, 2017. The self-reported diabetic patients were selected from each of the $\mathrm{CEB} /$ village using the following inclusion criteria.
Inclusion and exclusion criteria: Those aged 18 years and above with Type- 1 and Type- 2 diabetes was considered for the study. Persons below 18 , those who were seriously ill, and those with gestational diabetics were not considered for inclusion in the sample.

Quantitative tools: A structured interview schedule was used for capturing quantitative information. The first part of the interview schedule comprised questions to obtain household information and the second part for information on the respondent diabetics.

Lifestyle behaviour: Information on lifestyle behaviour of respondents was collected from the questions on how often they drink, consume tobacco/ghutka and smoke. Based on the responses, the responses were classified as high- and low-risk behaviours.

Blood sugar levels: Data on sugar levels (fasting and after meal) was collected from the medical reports of the respondents. A sugar levels were considered normal as $<100 \mathrm{gm} / \mathrm{dl}$ for fasting, and $<140 \mathrm{gm} / \mathrm{dl}$ after meal. Sugar levels more than these values indicated diabetic condition (Ministry of AYUSH, Govt. of India, 2015). Furthermore, types of morbidities data were obtained based on the medical report of diabetic persons. BMI was estimated from the height and weight of the respondents. BMI of less 18.5 indicated underweight, normal BMI is in the range 18.5-25, and a value of 25 and more indicated overweight or obese.

\subsection{Statistical methods}

Data entry performed using SPSS-22 software. Further, data was analysed by univariate, bivariate and multivariate techniques using SPSS-22 and STATA (Version 13.1) software. Univariate and bivariate has been used to show the comorbidities among diabetics by selected demographic and socio-economic variables. However, in multivariate techniques - Binary Logistics Regression were performed to see the effect of selected demographic and socio-economic variables.

\subsection{Ethical concerns}

Informed consent was obtained from community heads before the survey was initiated. Consent of individual respondents was also obtained before the interviews. Assurances were given to the respondents that they were free to withdraw from the study at any time. Since, study covered the health aspects of the diabetic persons. So, consent was also taken from the head of household and the diabetics to speak to their doctors. The purpose of the study was explained to the individual before the survey and promise to maintain privacy and confidentiality of data. Moreover, it would be used only for the purpose of an academic study.

\section{Results}

\subsection{Blood pressure}

Table 1 explored the association of major comorbidities with diabetic patients according to demographic and socioeconomics characteristics. About thirty-one percent of the diabetics from rural area and twenty-six percent from urban areas had blood pressure. It is higher among males (31.3\%) than females $(24.9 \%)$. Diabetics aged 60 years and above reported $42 \%$ high blood pressure, which is significantly higher than the prevalence among aged $18-40$ years (19.3\%) and $41-59$ years $(15.3 \%)$. Association between marital status and high blood pressure morbidities was also found to be significant $(\mathrm{P}<0.01)$. Prevalence of high blood pressure is higher among widowed, divorced, separated and never married respondents $(40.9 \%)$ than among those who were currently married (25.1\%). Moreover, significant association was found between education status of the respondents and their blood pressure $(\mathrm{P}<0.05)$. Illiterate had high blood pressure (33.3\%) than those had ten or more years of education (20.4\%). In Muslims, prevalence of high blood pressure was found $36.7 \%$, however, in Hindus was $26.3 \%$. A significant association was found between working status and high blood pressure 
Table 1

Comorbidities among diabetics by demographic and socio-economic characteristics.

\begin{tabular}{|c|c|c|c|c|c|c|c|c|c|c|c|c|c|c|c|c|c|c|c|c|}
\hline $\begin{array}{l}\text { Background } \\
\text { characteristics }\end{array}$ & $\begin{array}{l}\text { High Blood } \\
\text { pressure }\end{array}$ & $\mathrm{n}$ & $\chi^{2}$ & $\begin{array}{l}p \\
\text { value }\end{array}$ & $\begin{array}{l}\text { Cardiovascular } \\
\text { disease }\end{array}$ & $\mathrm{n}$ & $\chi^{2}$ & $\begin{array}{l}p \\
\text { value }\end{array}$ & Retinopathy & $\mathrm{n}$ & $\chi^{2}$ & $\begin{array}{l}p \\
\text { value }\end{array}$ & Rheumatology & $\mathrm{n}$ & $\chi^{2}$ & $\begin{array}{l}p \\
\text { value }\end{array}$ & Others & $\mathrm{n}$ & $\chi^{2}$ & $\begin{array}{l}p \\
\text { value }\end{array}$ \\
\hline \multicolumn{21}{|l|}{ Residence } \\
\hline Rural & 31.4 & 79 & 2 & 0.159 & 21.4 & 54 & 1.9 & 0.167 & 22.6 & 57 & 0.2 & 0.649 & 24.6 & 62 & 0.1 & 0.736 & 13.5 & 34 & 0.3 & 0.249 \\
\hline Urban & 25.7 & 65 & & & 16.6 & 42 & & & 21.0 & 53 & & & 23.3 & 59 & & & 11.9 & 30 & & \\
\hline \multicolumn{21}{|l|}{ Sex } \\
\hline Male & 31.3 & 89 & 2.5 & 0.111 & 18.3 & 52 & 0.2 & 0.649 & 16.9 & 48 & 9.1 & 0.003 & 21.5 & 61 & 2.2 & 0.139 & 13.4 & 38 & 0.3 & 0.523 \\
\hline Female & 24.9 & 55 & & & 19.9 & 44 & & & 28.1 & 62 & & & 27.2 & 60 & & & 11.8 & 26 & & \\
\hline \multicolumn{21}{|l|}{ Age (years) } \\
\hline $18-40$ & 19.3 & 16 & 41.9 & 0.000 & 12.1 & 10 & 14.5 & 0.001 & 10.8 & 9 & 16.8 & 0.000 & 12.1 & 10 & 26.2 & 0.000 & 10.8 & 9 & 0.5 & 0.522 \\
\hline $41-59$ & 15.3 & 29 & & & 13.2 & 25 & & & 16.9 & 32 & & & 16.4 & 31 & & & 12.2 & 23 & & \\
\hline 60 and above & 42.5 & 99 & & & 26.2 & 61 & & & 29.6 & 69 & & & 34.3 & 80 & & & 13.7 & 32 & & \\
\hline \multicolumn{21}{|l|}{ Marital status } \\
\hline Currently married & 25.1 & 99 & 10.6 & 0.001 & 18.7 & 74 & 0.1 & 0.765 & 19.5 & 77 & 5.6 & 0.018 & 22.0 & 87 & 3.7 & 0.054 & 11.1 & 44 & 3.9 & 0.045 \\
\hline $\begin{array}{l}\text { Widowed/divorced/ } \\
\text { separated/never } \\
\text { married }\end{array}$ & 40.9 & 45 & & & 20.0 & 22 & & & 30.0 & 33 & & & 30.9 & 34 & & & 18.2 & 20 & & \\
\hline \multicolumn{21}{|l|}{ Education status } \\
\hline Illiterate & 33.3 & 58 & 7.1 & 0.029 & 24.1 & 42 & 7.4 & 0.025 & 34.5 & 60 & 27.1 & 0.000 & 31.0 & 54 & 10.4 & 0.006 & 12.6 & 22 & 0.6 & 0.736 \\
\hline 1-9 years & 30.4 & 56 & & & 19.6 & 36 & & & 17.9 & 33 & & & 23.9 & 44 & & & 12.5 & 23 & & \\
\hline 10 and more years & 20.4 & 30 & & & 12.2 & 18 & & & 11.6 & 17 & & & 15.7 & 23 & & & 12.9 & 19 & & \\
\hline \multicolumn{21}{|l|}{ Religion } \\
\hline Hindu & 26.3 & 94 & 3.9 & 0.144 & 18.4 & 66 & 0.3 & 0.866 & 22.9 & 82 & 2.6 & 0.276 & 25.1 & 90 & 1.6 & 0.46 & 13.4 & 48 & 1.9 & 0.058 \\
\hline Muslim & 36.7 & 33 & & & 20.0 & 18 & & & 15.6 & 14 & & & 18.9 & 17 & & & 13.3 & 12 & & \\
\hline Buddhist and other & 29.8 & 17 & & & 21.1 & 12 & & & 24.6 & 14 & & & 24.6 & 14 & & & 7.0 & 4 & & \\
\hline \multicolumn{21}{|l|}{ Caste } \\
\hline SC/ST & 28.7 & 39 & 0.2 & 0.911 & 22.8 & 31 & 2.1 & 0.341 & 33.1 & 45 & 14.5 & 0.001 & 33.8 & 46 & 10 & 0.007 & 12.5 & 17 & 1.5 & 0.896 \\
\hline $\mathrm{OBC}$ & 27.0 & 31 & & & 15.7 & 18 & & & 20.0 & 23 & & & 20.9 & 24 & & & 9.6 & 11 & & \\
\hline General & 29.1 & 74 & & & 18.5 & 47 & & & 16.5 & 42 & & & 20.1 & 51 & & & 14.2 & 36 & & \\
\hline \multicolumn{21}{|l|}{ Working status } \\
\hline Not working & 35.6 & 91 & 18 & 0.000 & 22.7 & 58 & 4.7 & 0.096 & 28.9 & 74 & 17.4 & 0.000 & 30.1 & 77 & 11.1 & 0.004 & 13.7 & 35 & 2 & 0.122 \\
\hline $\begin{array}{l}\text { Farmer/daily wage } \\
\text { labour }\end{array}$ & 14.0 & 16 & & & 14.0 & 16 & & & 10.5 & 12 & & & 15.8 & 18 & & & 8.8 & 10 & & \\
\hline Other & 27.4 & 37 & & & 16.3 & 22 & & & 17.8 & 24 & & & 19.3 & 26 & & & 14.1 & 19 & & \\
\hline \multicolumn{21}{|l|}{ Wealth index } \\
\hline Poor & 29.2 & 49 & 0.4 & 0.828 & 19.1 & 32 & 0.3 & 0.869 & 16.7 & 28 & 4.5 & 0.103 & 23.2 & 39 & 0.7 & 0.701 & 11.9 & 20 & 0.6 & 0.179 \\
\hline Middle & 29.6 & 50 & & & 20.1 & 34 & & & 22.5 & 38 & & & 22.5 & 38 & & & 11.8 & 20 & & \\
\hline Rich & 26.8 & 45 & & & 17.9 & 30 & & & 26.2 & 44 & & & 26.2 & 44 & & & 14.3 & 24 & & \\
\hline Total & 28.5 & 144 & & & 19.0 & 96 & & & 21.8 & 110 & & & 24.0 & 121 & & & 12.7 & 64 & & \\
\hline
\end{tabular}

Note: the ' $n$ ' is reported based on the multiple responses but the percentage is given based on the total sample size $(n=505)$ not the total responses $(n=535)$. 
ailments $(\mathrm{P}<0.01)$. A higher proportion of blood pressure $(37.6 \%)$ was found in not working respondents whereas, it was $14 \%$ in farmer and daily wage workers.

\subsection{Cardiovascular disease}

Nineteen percent of diabetics people suffering with cardiovascular diseases (CVDs). Proportion of CVDs was seen higher in rural (21.4\%) than urban areas (16.6\%). It was slightly different among women (19.9\%) than men (18.3\%). The result highlights have a significant association between age and prevalence of CVDs $(\mathrm{P}<0.01)$. The prevalence of CVDs was significantly varying by age groups. It was higher in age group 60 and above years $(26.2 \%)$ than age group $18-40$ years (12.1\%). The findings show significant association between educational status and cardiovascular diseases $(\mathrm{P}<0.05)$. Illiterate had more cardiovascular diseases $(24.1 \%)$ than those with ten or more years of education (12\%). Furthermore, the prevalence of CVDs is more among SC/ STs $(22.8 \%)$ followed by OBC and general castes $(15.7 \%$ and $18.5 \%$ respectively). Working status is significantly associated with CVDs ailments $(\mathrm{P}<0.05)$. A larger proportion of diabetics, who were not working $(22.7 \%)$ had CVDs than farmers and daily wage workers (14\%). The prevalence of CVDs was $19.1 \%, 20.1 \%$ and $17.9 \%$ respectively in poor, middle and rich class (Table 1).

\subsection{Retinopathy}

Retinopathy is a common condition of eye problem among persons with diabetes. A slight difference was seen in the occurrence of retinopathy between rural and urban areas $-22.6 \%$ and $21 \%$ respectively. Further, prevalence of retinopathy was higher (28.1\%) among women, while it was $16.9 \%$ in men. Age of the respondents had a significant association with the prevalence of retinopathy $(\mathrm{P}<0.01)$. It was $10.8 \%$ among diabetics aged 18-40 years, and nearly three times more in 60 years and above (29.6\%). A greater prevalence of retinopathy (30\%) was observed among diabetics who were widowed, divorced, separated or never married, which is significantly more than those who were currently married (19.5\%). Education of respondents has significantly associated with retinopathy. Around $11.6 \%$ of illiterate diabetics reported retinopathy, while it was $34.5 \%$ among ten or more years of education. Caste was also significantly associated with retinopathy morbidities $(\mathrm{P}<0.01)$. The prevalence of retinopathy was higher (33.1\%) among diabetics SC/STs, which was more than that in the general castes $(16.5 \%)$. According to the wealth index, a higher percentage of diabetics in the rich class had retinopathy (26.2\%) than those in the poor category $(16.7 \%)$ (Table 1$)$.

\subsection{Rheumatism}

The prevalence of rheumatology was $24.6 \%$ and $23.3 \%$ among rural area and urban area respectively. Among diabetics, women had more rheumatology (27.2\%) than men (21.5\%). Findings show significant association between age and prevalence of rheumatology $(\mathrm{P}<0.01)$. Among diabetics aged 18-40 years, prevalence of rheumatology was $12.1 \%$, while it was $34.3 \%$ in 60 and above years. Marital status found significant association with rheumatism $(\mathrm{P}<0.05)$. Among respondents, who were widowed, divorced, separated and never married, prevalence of rheumatology was $30.9 \%$, which was higher than currently married (22\%) (Table 1). A significant association was seen between educational status and rheumatology ( $\mathrm{P}<0.01$ ). Prevalence was found to be higher among illiterate diabetics (34.5\%) than among those with ten or more years of education (11.6\%). A significant association was observed between caste and rheumatology $(\mathrm{P}<0.01)$. It was higher among the SC/ STs $(33.8 \%)$ than general caste $(20 \%)$. Further, significant association found between working status and rheumatology ailments $(\mathrm{P}<0.01)$. A finding showed higher prevalence of rheumatology in not working $(30.1 \%)$ as compared to farmers/daily wage labourers $(15.8 \%)$
(Table 1).

\subsection{Other morbidities}

The prevalence of others morbidities (asthma, kidney disease, foot ulcers or infections, strokes, nerve disease, thyroid disease, skin problems, anaemia, injury and problems of teeth and gums) did not vary much between rural and urban areas (13.5\% and $11.9 \%$ respectively). Additional, significant association was seen between marital status and other morbidities $(\mathrm{P}<0.05)$. It was higher $(18.2 \%)$ among widowed, divorced, separated and unmarried diabetics than currently married (11.1\%). Among Buddhists and other religions, the prevalence of other morbidities was 7\%, which was lower than Hindus and Muslims (13.4\% and $13.3 \%$ respectively). Prevalence of comorbidities was lower among diabetics' farmers and daily wage workers (8\%) than among the diabetics not working (13.4\%) (Table 1).

\subsection{Association of health risk factors with comorbidities}

Table 2 reveals the prevalence of comorbidities among persons with diabetes by health risk factors. The prevalence of high blood pressure was more among people with higher fasting blood sugar level (30.3\%) than normal fasting blood sugar level (24.9). However, after meal blood sugar levels was significantly associated with blood pressure $(\mathrm{P}<0.01)$. Among diabetics, the prevalence of blood pressure is found to be higher $(31.8 \%)$ in those with high blood sugar levels after meal than those with normal blood sugar levels (19.7\%). Further, significant association was seen between adherence to a daily treatment routine and blood pressure $(\mathrm{P}<0.01)$. Proportion of insulin-dependent diabetics $(50 \%)$ had high blood pressure than those who were taking oral medication (23.9\%). In addition, BMI was seen to be significantly associated with the prevalence of blood pressure $(\mathrm{P}<0.01)$. It was more among overweight diabetics (37.9\%) than underweight (18.4\%) and normal diabetics (19.6\%). About $32 \%$ of diabetics did not exercise daily, had higher blood pressure than diabetics exercised daily (26.6\%). Furthermore, significant association was observed between daily exercise and high blood pressure $(\mathrm{P}$ $<0.05)$. In addition, substance use plays a significant role with prevalence of blood pressure $(\mathrm{P}<0.05)$. A higher proportion of substance consumers (33\%) had high blood pressure than those who did not use substance $(25.3 \%)$.

Diabetics with high fasting sugar had a higher prevalence of cardiovascular diseases (20.3\%). It was less among those with normal blood sugar level $(16.4 \%, \mathrm{P}<0.05)$. Among those with high blood sugar levels after meal, prevalence of CVDs was $21.5 \%$, which is higher than that among diabetics with normal after meal blood sugar levels (12.4\%). Marginal difference was seen in the prevalence of CVDs between diabetics who are insulin-dependent and those who take oral medication ( $20 \%$ and $18 \%$ respectively). The association between BMI and cardiovascular disease is significant at $5 \%$ level of significance. It is higher (23.8\%) among overweight as compared with those of normal BMI $(13.7 \%)$. Composition of every day exercise has significant association with cardiovascular disease $(\mathrm{P}<0.01)$. Diabetics who exercise daily tended less to suffer from CVDs-prevalence was $15.6 \%$ - than those who did not do daily exercise (21.5\%). A significant association was seen between substance use and prevalence of CVDs $(\mathrm{P}<0.01)$. Substance users showed higher prevalence of CVDs (24.5\%) than those who did not use (15\%) (Table 2).

Association was significant between daily exercise diabetics and retinopathy $(\mathrm{P}<0.01)$. The prevalence of retinopathy in diabetics was $22.7 \%$ and $20 \%$ among high fasting blood sugar, and those had normal fasting blood sugar level respectively. Among those had high blood sugar levels after meal, $22 \%$ had retinopathy, which was marginally higher than of those with normal blood sugar levels (21.2\%). Overweigh diabetics showed higher prevalence of retinopathy (23\%) than those were underweight (15.8\%) and normal BMI (21.5\%). Prevalence of Retinopathy was higher in diabetics who did not exercise daily (26.6\%) 


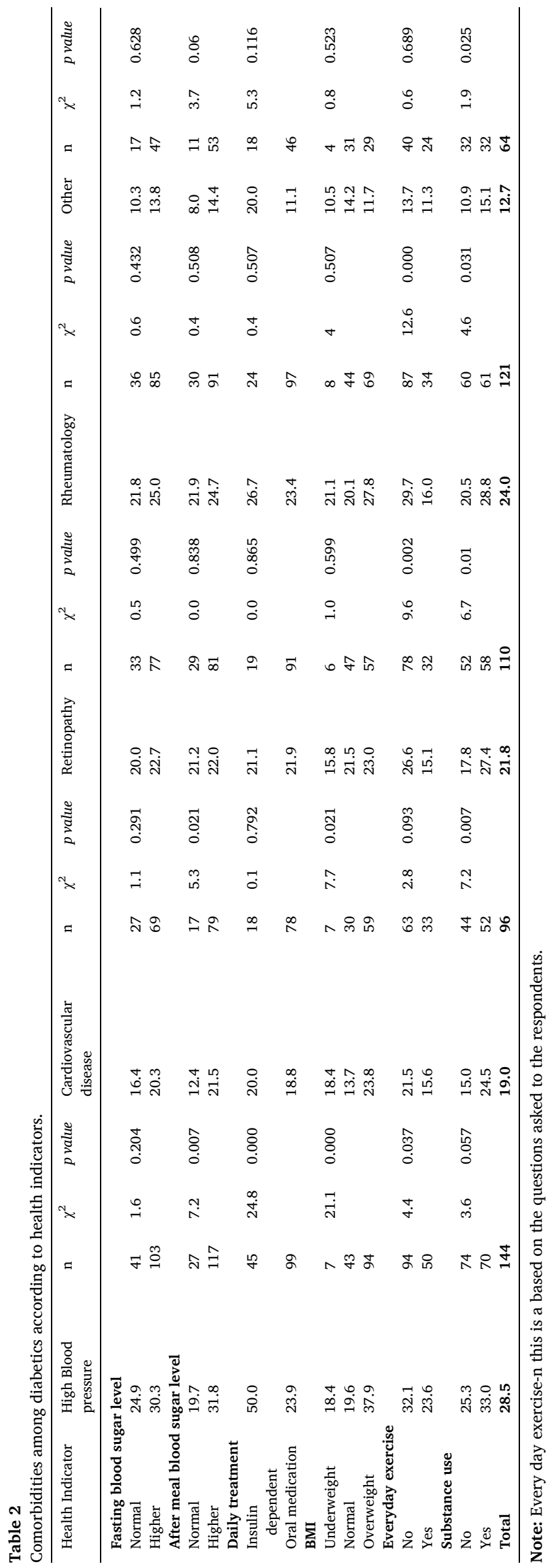

than those did (15.1\%). Furthermore, substance user had significant association with the prevalence of retinopathy $(\mathrm{P}<0.01)$. Around $27.4 \%$ substance users had retinopathy (Table 2 ).

A slight difference was found in the prevalence of rheumatology between diabetics had high fasting blood sugar level and those whose fasting blood sugar level was normal. About 25\% diabetics with higher fasting blood sugar and $21.8 \%$ diabetics with normal fasting sugar level had rheumatology. Around $24.7 \%$ diabetics with high blood sugar after meal had rheumatology however, $21.9 \%$ in normal blood sugar after meal. A significant association was found between BMI and rheumatology ( $\mathrm{P}<0.01$ ). The results showed $27.8 \%$ overweight diabetics had rheumatology, which was present in $21.1 \%$ for the underweight and $20 \%$ for normal BMI. Daily exercise was found to have a significant association with rheumatology ( $\mathrm{P}<0.01$ ). The prevalence of rheumatology among diabetics who did not exercise daily was $29.7 \%$. Among those who exercised daily, $16 \%$ had rheumatology. Substance's consumers Diabetics had 28.8\% rheumatology, however, in not substance user, smaller proportion had rheumatology (20.5\%) (Table 2).

Table 3 shown the numbers of comorbidities among diabetic persons by demographic and socioeconomics characteristics. The numbers of comorbidities were $18.8 \%, 19 \%$ and $14.4 \%$ respectively by one comorbidity, two comorbidities and three numbers comorbidities among diabetics' persons. The number of three and above comorbidities with diabetes was in $16.7 \%$ in rural areas, and $11.9 \%$ in urban. Furthermore, three and above comorbidities in diabetic persons was higher among males (15.5\%) compared to female (12.7\%). The prevalence of three and above comorbidities was also seen higher among age group 60 and above years (22.3\%), whereas it was 6\% in age group 18-40 years $(\mathrm{P}<$ $0.01)$. Education level had negative association with number of morbidities $(\mathrm{P}<0.01)$. Three and more numbers of morbidities was in $10.9 \%$ among the diabetics having 10 and more years of educated, while it was higher among illiterate (19.5\%). Similarly, caste has significantly associated with numbers of comorbidities $(P<0.05)$. Prevalence of three and more numbers of comorbidities were $18.4 \%$ in SC/ST, while it was $11.3 \%$ and $13.4 \%$ respectively in OBC and general castes. Three and more numbers of morbidities was significantly higher among not working respondents (18.4\%) than farmer and daily wage labours (7.8\%, p $<0.01)$.

Table 4 reveals the prevalence of multiple morbidities by health risk factors. BMI was significantly associated with numbers of morbidities ( $P$ $<0.01$ ). The prevalence of three and more number of comorbidities found to be $10.1 \%$ among respondents with normal BMI, while it was higher in overweight (18.2\%). Daily exercise was also significantly associated with numbers of comorbidities $(\mathrm{P}<0.01)$. The prevalence of three and more numbers of comorbidities was higher (17.4\%) in those who did not do daily exercise than those did daily exercise $(9.9 \%)$. Similar, substance use was significantly associated with numbers of comorbidities $(\mathrm{P}<0.01)$. The higher prevalence of three and more numbers of comorbidities was in substance user $(22.6 \%)$ than non substance user (8.2\%).

\section{Result of binary logistic regression models}

Table 5 presents the outcome of binary logistic regression to determine the association of blood pressure of the diabetics. Women had $50 \%$ less chances to be diabetics than men of being diagnosed with high blood pressure. Aged 60 years and more were found to be 2.3 times more likely to have blood pressure than aged $18-40$ years $(P<0.05)$. Diabetic farmers and daily wage workers were $60 \%$ less likely to have high blood pressure than those who were not working $(\mathrm{P}<0.001)$. Daily treatment was significantly associated with prevalence of high blood pressure $(\mathrm{P}<$ 0.001). Diabetics on oral medication were $70 \%$ less likely to have high blood pressure than those were insulin dependent. Furthermore, overweight diabetics are 2.5 times more likely to have high blood pressure than those with a normal BMI $(\mathrm{P}<0.001)$. Similarly, marital status was significantly associated with cardiovascular disease $(P<0.05)$. Diabetic 
Table 3

Numbers of comorbidities among diabetic persons by demographic and socioeconomics characteristics, Latur district, 2017.

\begin{tabular}{|c|c|c|c|c|c|c|c|c|c|}
\hline \multirow[t]{2}{*}{ Background Characteristics } & \multicolumn{2}{|l|}{ One } & \multicolumn{2}{|l|}{ Two } & \multicolumn{2}{|c|}{ Tree and above } & \multirow[t]{2}{*}{$\chi^{2}$} & \multirow[t]{2}{*}{ p value } & \multirow[t]{2}{*}{$\mathrm{N}$} \\
\hline & $\%$ & $\mathrm{n}$ & $\%$ & $\mathrm{n}$ & $\%$ & $\mathrm{n}$ & & & \\
\hline \multicolumn{10}{|l|}{ Locality } \\
\hline Rural & 17.5 & 44 & 19.4 & 49 & 16.7 & 42 & 2.8 & 0.31 & 252 \\
\hline Urban & 20.2 & 51 & 18.6 & 47 & 11.9 & 30 & & & 253 \\
\hline \multicolumn{10}{|l|}{ Sex } \\
\hline Male & 17.6 & 50 & 15.5 & 44 & 15.5 & 44 & 7.1 & 0.123 & 284 \\
\hline Female & 20.4 & 45 & 23.5 & 52 & 12.7 & 28 & & & 221 \\
\hline \multicolumn{10}{|l|}{ Age } \\
\hline $18-40$ & 22.9 & 19 & 10.8 & 9 & 6.0 & 5 & 47 & 0.000 & 83 \\
\hline $41-59$ & 18.0 & 34 & 14.8 & 28 & 7.9 & 15 & & & 189 \\
\hline 60 and above & 18.0 & 42 & 25.3 & 59 & 22.3 & 52 & & & 233 \\
\hline \multicolumn{10}{|l|}{ Marital status } \\
\hline Currently married & 17.7 & 70 & 18.7 & 74 & 12.4 & 49 & 9.5 & 0.053 & 395 \\
\hline Widowed/divorced/separated/Never married & 22.7 & 25 & 20.0 & 22 & 20.9 & 23 & & & 110 \\
\hline \multicolumn{10}{|l|}{ Education Status } \\
\hline Non literate & 21.8 & 38 & 22.4 & 39 & 19.5 & 34 & 27.4 & 0.001 & 174 \\
\hline $1-9$ years & 20.1 & 37 & 21.7 & 40 & 12.0 & 22 & & & 184 \\
\hline 10 and more & 13.6 & 20 & 11.6 & 17 & 10.9 & 16 & & & 147 \\
\hline \multicolumn{10}{|l|}{ Religion } \\
\hline Hindu & 17.6 & 63 & 20.4 & 73 & 13.7 & 49 & 7.3 & 0.531 & 358 \\
\hline Muslim & 23.3 & 21 & 20.0 & 18 & 12.2 & 11 & & & 90 \\
\hline Buddhist and Other & 19.3 & 11 & 8.8 & 5 & 21.1 & 12 & & & 57 \\
\hline \multicolumn{10}{|l|}{ Caste } \\
\hline SC/ST & 19.1 & 26 & 24.3 & 33 & 18.4 & 25 & 13.1 & 0.031 & 136 \\
\hline OBC & 24.4 & 28 & 13.0 & 15 & 11.3 & 13 & & & 115 \\
\hline General & 16.1 & 41 & 18.9 & 48 & 13.4 & 34 & & & 254 \\
\hline \multicolumn{10}{|l|}{ Working Status } \\
\hline Currently not working & 21.9 & 56 & 24.6 & 63 & 17.2 & 44 & 33.6 & 0.001 & 256 \\
\hline Farmer/daily wage labour & 16.7 & 19 & 9.7 & 11 & 7.9 & 9 & & & 114 \\
\hline Other & 14.8 & 20 & 16.3 & 22 & 14.1 & 19 & & & 135 \\
\hline \multicolumn{10}{|l|}{ Wealth Index } \\
\hline Poor & 18.5 & 31 & 17.3 & 29 & 14.3 & 24 & 2.1 & 0.192 & 168 \\
\hline Middle & 21.3 & 36 & 18.3 & 31 & 13.6 & 23 & & & 169 \\
\hline Rich & 16.7 & 28 & 21.4 & 36 & 14.9 & 25 & & & 168 \\
\hline Total & $\overline{18.8}$ & $\overline{95}$ & $\overline{19.0}$ & $\overline{96}$ & $\overline{14.3}$ & 72 & & & $\overline{505}$ \\
\hline
\end{tabular}

Table 4

Numbers of comorbidities in diabetic persons according to health indicators, Latur district, 2017.

\begin{tabular}{|c|c|c|c|c|c|c|c|c|c|}
\hline \multirow[t]{2}{*}{ Health indicators } & \multicolumn{2}{|l|}{ One } & \multicolumn{2}{|l|}{ Two } & \multicolumn{2}{|c|}{ Three and above } & \multirow[t]{2}{*}{$\chi^{2}$} & \multirow[t]{2}{*}{ p value } & \multirow[t]{2}{*}{$\mathrm{N}$} \\
\hline & $\%$ & $\mathrm{n}$ & $\%$ & $\mathrm{n}$ & $\%$ & $\mathrm{n}$ & & & \\
\hline \multicolumn{10}{|c|}{ Fasting blood sugar level } \\
\hline Normal & 17.6 & 29 & 14.6 & 24 & 13.9 & 23 & 4.6 & 0.351 & 165 \\
\hline Higher & 19.4 & 66 & 21.2 & 72 & 14.4 & 49 & & & 340 \\
\hline \multicolumn{10}{|c|}{$\overline{\text { After meal blood sugar level }}$} \\
\hline Normal & 20.4 & 28 & 11.7 & 16 & 12.4 & 17 & 8.3 & 0.042 & 137 \\
\hline Higher & 18.2 & 67 & 21.7 & 80 & 15.0 & 55 & & & 368 \\
\hline \multicolumn{10}{|l|}{ Daily treatments } \\
\hline Insulin dependant & 21.1 & 19 & 35.6 & 32 & 13.3 & 12 & 23.5 & 0.001 & 90 \\
\hline Oral medication & 18.3 & 76 & 15.4 & 64 & 14.5 & 60 & & & 415 \\
\hline \multicolumn{10}{|l|}{ BMI } \\
\hline Underweight & 7.9 & 3 & 15.8 & 6 & 13.2 & 5 & 15.6 & 0.000 & 38 \\
\hline Normal & 18.3 & 40 & 17.8 & 39 & 10.1 & 22 & & & 219 \\
\hline Overweight & 21.0 & 52 & 20.6 & 51 & 18.2 & 45 & & & 248 \\
\hline \multicolumn{10}{|l|}{ Every day exercise } \\
\hline No & 16.7 & 49 & 22.9 & 67 & 17.4 & 51 & 15.5 & 0.001 & 293 \\
\hline Yes & 21.7 & 46 & 13.7 & 29 & 9.9 & 21 & & & 212 \\
\hline \multicolumn{10}{|l|}{ Substance use } \\
\hline No & 22.9 & 67 & 18.8 & 55 & 8.2 & 24 & 24.9 & 0.002 & 293 \\
\hline Yes & 13.2 & 28 & 19.3 & 41 & 22.6 & 48 & & & 212 \\
\hline Total & 18.8 & 95 & 19.0 & $\overline{96}$ & 14.3 & 72 & & & 505 \\
\hline
\end{tabular}


Table 5

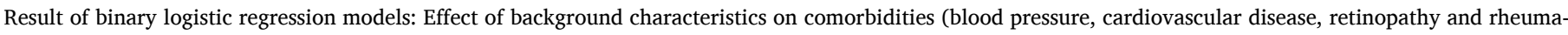
tology) among diabetic persons.

\begin{tabular}{|c|c|c|c|c|c|c|c|c|}
\hline \multirow[t]{2}{*}{ Background characteristics } & \multicolumn{2}{|c|}{ High Blood Pressure } & \multicolumn{2}{|c|}{ Cardiovascular disease } & \multicolumn{2}{|c|}{ Retinopathy } & \multicolumn{2}{|c|}{ Rheumatology } \\
\hline & AOR & 95\% C.I. & AOR & 95\% C.I. & AOR & 95\% C.I. & AOR & 95\% C.I. \\
\hline \multicolumn{9}{|l|}{ Locality } \\
\hline Rural ${ }^{\circledR}$ & 1 & & 1 & & 1 & & 1 & \\
\hline Urban & 0.8 & $(0.51,1.29)$ & 0.8 & $(0.46,1.25)$ & 1 & $(0.62,1.66)$ & 1 & $(0.65,1.63)$ \\
\hline \multicolumn{9}{|l|}{ Sex } \\
\hline Male ${ }^{\circledR}$ & 1 & & 1 & & 1 & & 1 & \\
\hline Female & $0.5^{* * *}$ & $(0.27,0.82)$ & 1.2 & $(0.63,2.16)$ & $1.9^{* *}$ & $(1.01,3.54)$ & 1.2 & $(0.7,2.2)$ \\
\hline \multicolumn{9}{|l|}{$\overline{\text { Age }}$} \\
\hline $18-40 \AA$ & 1 & & 1 & & 1 & & 1 & \\
\hline $41-59$ & 0.7 & $(0.32,1.49)$ & 0.8 & $(0.36,1.95)$ & 1 & $(0.43,2.43)$ & 1.1 & $(0.49,2.48)$ \\
\hline 60 and above & $2.3^{* *}$ & $(1.07,4.9)$ & 1.8 & $(0.75,4.21)$ & 1.7 & $(0.7,4.11)$ & $2.9^{* * *}$ & $(1.26,6.56)$ \\
\hline \multicolumn{9}{|l|}{ Marital status } \\
\hline Currently married ${ }^{\circledR}$ & 1 & & 1 & & 1 & & 1 & \\
\hline Widowed/divorced/separated/never married & 1.2 & $(0.65,2.05)$ & $0.5^{* *}$ & $(0.27,1.02)$ & 0.7 & $(0.37,1.33)$ & 0.8 & $(0.41,1.38)$ \\
\hline \multicolumn{9}{|l|}{ Education status } \\
\hline Non literate ${ }^{\circledR}$ & 1 & & 1 & & 1 & & 1 & \\
\hline $1-9$ years & 1 & $(0.58,1.81)$ & 0.9 & $(0.48,1.59)$ & $0.5^{* * *}$ & $(0.27,0.87)$ & 1 & $(0.54,1.68))$ \\
\hline 10 and more & 0.8 & $(0.39,1.66)$ & 0.6 & $(0.27,1.30)$ & $0.3^{* * *}$ & $(0.15,0.72)$ & 0.8 & $0.39,1.64)$ \\
\hline \multicolumn{9}{|l|}{ Religion } \\
\hline Hindu ${ }^{\circledR}$ & 1 & & 1 & & 1 & & 1 & \\
\hline Muslim & 1.2 & $(0.68,2.28)$ & 1.0 & $(0.52,2.04)$ & 0.7 & $(0.33,1.38)$ & 0.7 & $(0.37,1.4)$ \\
\hline Buddhist and Other & 0.8 & $(0.37,1.96)$ & 0.9 & $(0.37,2.02)$ & 0.6 & $(0.27,1.43)$ & $0.5^{*}$ & $(0.23,1.15)$ \\
\hline \multicolumn{9}{|l|}{ Caste } \\
\hline $\mathrm{SC} / \mathrm{ST} \circledast$ & 1 & & 1 & & 1 & & 1 & \\
\hline OBC & 0.7 & $(0.32,1.38)$ & 0.6 & $(0.25,1.20)$ & $0.4^{* *}$ & $(0.21,0.89)$ & $0.4^{* * *}$ & $(0.18,0.72)$ \\
\hline General & 0.8 & $(0.44,1.63)$ & 0.7 & $(0.38,1.44)$ & $0.4^{* * *}$ & $(0.19,0.71)$ & $0.4^{* * *}$ & $(0.2,0.7)$ \\
\hline \multicolumn{9}{|l|}{ Working status } \\
\hline Currently not working ${ }^{\circledR}$ & 1 & & 1 & & 1 & & 1 & \\
\hline Farmer/daily wage labour & $0.4^{* * *}$ & $(0.18,0.8)$ & 0.8 & $(0.37,1.55)$ & $0.4^{* * *}$ & $(0.18,81$ & 0.7 & $(0.35,1.34)$ \\
\hline Other & 0.9 & $(0.47,1.61)$ & 1.0 & $(0.51,2.00)$ & 1.1 & $(0.54,2.08)$ & 1 & $(0.52,1.83)$ \\
\hline \multicolumn{9}{|l|}{ Wealth index } \\
\hline Poor ${ }^{\circledR}$ & 1 & & 1 & & 1 & & 1 & \\
\hline Middle & 1.2 & $(0.7,2.1)$ & 1.3 & $(0.73,2.38)$ & $2.2^{* * *}$ & $(1.19,4.23)$ & 1.2 & $(0.68,2.11)$ \\
\hline Rich & 0.8 & $(0.43,1.33)$ & 1.0 & $(0.52,2.38)$ & $2.5^{* * *}$ & $(1.38,4.62)$ & 1.3 & $(0.76,2.31)$ \\
\hline \multicolumn{9}{|l|}{ Fasting sugar level } \\
\hline Normal $\mathbb{B}$ & 1 & & 1 & & 1 & & 1 & \\
\hline Higher & 1.1 & $(0.62,1.97)$ & 1.0 & $(0.52,1.82)$ & 1.3 & $(0.69,2.37)$ & 1.1 & $(0.65,2.05)$ \\
\hline \multicolumn{9}{|l|}{ After meal sugar level } \\
\hline Normal $®$ & 1 & & 1 & & 1 & & 1 & \\
\hline Higher & 1.1 & $(0.6,2.11)$ & 1.6 & $(0.78,3.17)$ & 0.7 & $(0.39,1.43)$ & 0.8 & $(0.46,1.56)$ \\
\hline \multicolumn{9}{|l|}{ Daily treatment } \\
\hline Insulin dependent ${ }^{\circledR}$ & 1 & & 1 & & 1 & & 1 & \\
\hline Oral medication & $0.3^{* * *}$ & $(0.16,0.48)$ & 0.9 & $(0.50,1.73)$ & 1 & $(0.5,1.8)$ & 0.8 & $(0.45,1.45)$ \\
\hline \multicolumn{9}{|l|}{ BMI } \\
\hline Normal $®$ & 1 & & 1 & & 1 & & 1 & \\
\hline Overweight & $2.5^{* * *}$ & $(1.57,4.04)$ & $1.7^{* *}$ & $(1.02,2.76)$ & 0.9 & $(0.58,1.53))$ & $1.5^{*}$ & $(0.92,2.31)$ \\
\hline Exercising daily & & & & & & & & \\
\hline No $\mathbb{R}$ & 1 & & 1 & & 1 & & 1 & \\
\hline Yes & 0.8 & $(0.47,1.23)$ & 0.8 & $(0.46,1.29)$ & $0.6^{* *}$ & $(0.36,1.03)$ & $0.5^{* * *}$ & $(0.29,0.78)$ \\
\hline Substance use & & & & & & & & \\
\hline No ${ }^{\circledR}$ & 1 & & 1 & & 1 & & 1 & \\
\hline Yes & 1.2 & $(0.7,1.96)$ & $2.0 * * *$ & $(1.16,3.53)$ & $2.4^{* * *}$ & $(1.34,4.24)$ & 1.3 & $(0.79,2.27)$ \\
\hline
\end{tabular}

Note 1: ${ }^{* * *}$ P value $<0.01,{ }^{* * P}$ value $<0.05, * P$ value $<0.10,{ }^{\circledR}$ - Reference category.

Note 2: AOR - Adjusted Odds Ratios.

Note 3: High blood pressure, Retinopathy and Rheumatology was independent questions asked from individual respondents.

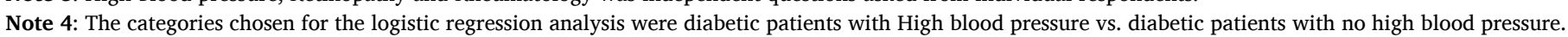
Similarly, the categories chosen for the logistic regression analysis were diabetic patients with Retinopathy vs. diabetic patients with no Retinopathy and so on.

widowed, divorced, separated and never married were 1.2 time more likely to have cardiovascular disease than those with currently married. Remarkable, overweight diabetics are 1.7 times more likely to have cardiovascular disease than those with normal BMI $(\mathrm{P}<0.05)$. Interestingly, Substance use by diabetics are 2 time more likely to have cardiovascular disease than those not use substance $(\mathrm{P}<0.05)$.
Female diabetics were found to be 1.9 times more likely to be diagnosed with retinopathy than male diabetics $(\mathrm{P}<0.05)$. Similarly, diabetics belongs to OBCs and general castes were found to have $60 \%$ less chances of being diagnosed with retinopathy than the SC/ST castes $(\mathrm{P}<0.001)$. Diabetics in farmers and daily wage labourers had $60 \%$ less chances of having retinopathy than those diabetics not working $(\mathrm{P}<$ 
0.005). The association of wealth status was significant with retinopathy morbidities $(P<0.001)$. Diabetics from the middle class and rich class were found to be, respectively, 2.2 and 2.5 times more likely to be diagnosed with retinopathy than those from the poor class. A significant association was seen in daily exercise with prevalence of retinopathy ( $P$ $<0.05$ ). Diabetics who were exercise daily had $40 \%$ less chances than those who do not exercise daily of being diagnosed with retinopathy. Diabetics who use substances were 2.4 times more retinopathy ailment than non-users.

The association is significant between age of respondents and rheumatology ailments $(\mathrm{P}<0.001)$. Diabetics aged 60 years and above were 2.9 times more likely to be diagnosed with rheumatology as compared with diabetics aged 18-40 years. Religion is significantly associated with prevalence of rheumatology ailment $(\mathrm{P}<0.05)$. Respondents belonging to Buddhist and other religions were $50 \%$ less rheumatology ailment than Hindus. The results of binary logistic regression also show the significantly association of daily exercise with the likelihood of rheumatology in diabetics ( $\mathrm{P}<0.001)$. Those exercising daily had $50 \%$ less chances of having rheumatology ailments than those who do not.

\section{Discussion}

Epidemiology of non-communicable diseases (NCDs) has become major health issues among India. Diabetes is one of the important components of NCDs. The proportion of diabetes is increasing, and it is a cause of several risk factors, which were classified into modifiable and non-modifiable risk factors. Modifiable factors include obesity, sedentary lifestyles, improper diet, stress, alcohol and viral infections. ${ }^{5,7,8}$ However, non-modifiable risk factors include socio-economic status, genetic predisposition to the disease and family history. ${ }^{10,11}$ Around one third to half of diabetic patients are living with one or more types of morbidities. ${ }^{13}$ According to DLHS-4 (2012-13), in Latur, 14\% of the population reported more than $140 \mathrm{mg} / \mathrm{Id}$ blood sugar level. In the NFHS-4 (2015-16), this figure had increased to $17 \%$, indicates a significant change in the particular place, and therefore this study was carried out to highlight the burden of comorbidities among diabetes, its symptoms and socio-demographic, economic and health determinants.

Hypertension and rheumatology comorbidities were high among the diabetic persons. Finding is supported by past studies, and reported approximate findings of higher prevalence of co-morbidities among diabetic peoples. The prevalence of comorbidities is observed to be higher among 60 and above population due to less physical activities, illness and lack of health management. Moreover, age is a nonmodifiable risk factors of comorbidities. ${ }^{23}$ Widowed, divorced and separated diabetics have experienced higher levels of hypertension, rheumatology and retinopathy compared with currently married. Reason is in this marital status higher proportion of people use substance and suffered with obese and overweight ailments. ${ }^{14}$ The possible reasons reported for higher prevalence of diabetics are overweight/obesity, less physical activity, increased blood glucose and cholesterol level. ${ }^{15}$

The educational status of diabetics has been associated with the prevalence of comorbidities. Illiterate diabetics are at greater risk of comorbidities (blood pressure, cardiovascular disease, retinopathy, and rheumatology). The higher level of education is observed to increase the awareness about symptoms and risk factors of diabetes at individual level, and proper health managements to prevent diabetes and its association with comorbidities. ${ }^{16,17}$ Focusing on wide range of health education programmes in rural areas for diabetic's risk factors, consequences and comorbidities associated with diabetes would help in reduction in the occurrence of diabetics. Targeting high risk population for early health checks in community settings could lead to identify population in early phase of disease.

The SCs/STs and OBC suffered more from multiple morbidities than general caste group of population. This may be attributed to pre-existing poor quality of life and poor available quality of medical care, lack of awareness and poor economic status. Previous studies also noted that population belonging to poor socio-economic status have lower level of educations, lack of awareness regarding health and lower level of treatment compliances. ${ }^{12,18}$ Women and respondents belonging to Muslim religion and poor wealth households have experienced higher levels of comorbidities than their counterparts. This may be attributed to the life style behavior, socio-economic status pride and honor, less physical activity and increased overweight/obesity. The earlier research also finds similar results. ${ }^{15,19,20}$ Due to higher sugar level, lack of exercise, overweight and obesity more diabetic persons suffer from symptoms of morbidities like joint pain, chest pain, eye problem, energy decrease. ${ }^{21}$ It is commonly known that obesity, high-fat, high-sodium diet and inactivity lead to increase in both diabetes and hypertension, heart disease, rheumatism and eye problem. ${ }^{22}$

\section{Conclusion}

Majority of diabetic's person were suffered with overweight and high blood sugar levels, due to higher dietary intake with calories, fibber and fat. These risk factors increased proportion of overweight or obesity and diabetes ailments. The prevalence of selected co-morbidities (blood pressure, cardiovascular diseases, retinopathy and rheumatology) is higher among diabetic's patients. Due to sedentary life style, more consumption of substance use, lack of exercise and lack of awareness about managements of diabetes, people were unable to prevent comorbidities. Hence, awareness about diabetes prevention and management is required through health education, disease management programmes, trained peers and community health workers and communitybased programmes.

\section{Ethical Approval and consent to participate}

Ethical Approval was taken from the 'International Institute for Population Sciences, Mumbai'. Moreover, before conducting the interview, consent was taken from the respondents.

\section{Consent for publication}

Not applicable.

\section{Availability of supporting data}

This study is based on Primary data.

\section{Funding}

Not received any funding.

\section{Declaration of competing interest}

We hereby declare that the article entitled "Burden of comorbidities among diabetic patients in Latur, India" does not have any conflict of interest involved.

We also declared that this research article is nowhere submitted for publication.

\section{Acknowledgements}

Not applicable.

\section{References}

1 Shetty R, Jena B, Kadithi A. Can social scientists be the change agents for diabetes prevention? Diabetes-related knowledge, attitude, and practice among social scientists. J Soc Health Diabetes. 2013;1(1):32-36.

2 Bansode B, Nagarajan R. Diabetes: a review of awareness, comorbidities, and quality of life in India. J Soc Health Diabetes. 2017;5(2):77. 
3 Deepa D, Kiran B, Gadwalkar SR. Macrovascular and microvascular complications in newly diagnosed type 2 diabetes mellitus. Indian J Clin Pract. 2014;25(7).

4 Bray GA, Popkin BM. Dietary sugar and body weight: have we reached a crisis in the epidemic of obesity and diabetes?: health be damned! Pour on the sugar. Diabetes Care. 2014;37(4):950-956.

5 Chan JC, Malik V, Jia W, et al. Diabetes in Asia: epidemiology, risk factors, and path physiology. JAMA. 2009;301:2129-2140.

6 Mohan V, Seedat YK, Pradeepa R. The rising burden of diabetes and hypertension in southeast asian and african regions: need for effective strategies for prevention and control in primary health care settings. Int J Hypertens. 2013;2013.

7 Vigneswari A, Manikandan R, Satyavani K, Archana S, Rajeswari R, Viswanathan V. Prevalence of risk factors of diabetes among urban poor south Indian population. J Assoc Phys India. 2015;63(10):32-34.

8 Mohan V, Sandeep S, Deepa R, Shah B, Varghese C. Epidemiology of type 2 diabetes: Indian Scenario. Indian J Med Res. 2007;125:217-230.

9 Wild S, Roglic G, Green A, Sicree R, King H. Global prevalence of diabetes: estimates for the year 2000 and projections for 2030. Diabetes Care. 2004;27, 1047-5.

10 Kinra S, Bowen LJ, Lyngdoh T, et al. Socio-demographic patterning of noncommunicable disease risk factors in rural India: a cross sectional study. BMJ. 2010; 341:c4974.

11 Majgi SM, Soudarssanane BM, Roy G, Das AK. Risk factors of diabetes mellitus in rural Puducherry. Online J Health Allied Sci. 2012;11(1):4.

12 Piette JD, Kerr EA. The impact of comorbid chronic conditions on diabetes care. Diabetes Care. 2006;29(3):725-731.

13 Ramachandran A, Snehalatha C, Viswanathan V. Burden of type 2 diabetes and its complications-the Indian scenario. Curr Sci Bangalore. 2002;83(12):1471-1476.
14 De Oliveira CM, Viater Tureck L, Alvares D, Liu C, Horimoto ARVR, Balcells M, Pereira AC. Relationship between marital status and incidence of type 2 diabetes mellitus in a Brazilian rural population: the Baependi Heart Study. PLoS One. 2020; 15(8), e0236869.

15 Mbanya JCN, Motala AA, Sobngwi E, Assah FK, Enoru ST. Diabetes in sub-saharan africa. Lancet. 2010;375(9733):2254-2266.

16 Murugesan N, Snehalatha C, Shobhana R, Roglic G, Ramachandran A. Awareness about diabetes and its complications in the general and diabetic population in a city in southern India. Diabetes Res Clin Pract. 2007;77(3):433-437.

17 Azimi-Nezhad M, Ghayour-Mobarhan M, Parizadeh MR, et al. Prevalence of type 2 diabetes mellitus in Iran and its relationship with gender, urbanisation, education, marital status and occupation. Singap Med J. 2008;49(7):571-576.

18 Saydah SH, Imperatore G, Beckles GL. Socioeconomic status and mortality: contribution of health care access and psychological distress among US adults with diagnosed diabetes. Diabetes Care. 2013;36(1):49-55.

19 Swai ABM, McLarty DG, Sherrif F, et al. Diabetes and impaired glucose tolerance in an Asian community in Tanzania. Diabetes Res Clin Pract. 1990;8(3):227-234.

20 Ramaiya KL, Kodali VRR, Alberti KGMM. Epidemiology of diabetes in Asians of the Indian subcontinent. Diabetes Metab Rev. 1990;6(3):125-146.

21 Pati S, Pati S, van den Akker M, Schellevis FFG, Sahoo K, Burgers JS. Managing diabetes mellitus with comorbidities in primary healthcare facilities: a qualitative study among physicians in Odisha, India. Res Square. 2020;(1):1-20.

22 Cheung BM, Li C. Diabetes and hypertension: is there a common metabolic pathway? Curr Atherosclerosis Rep. 2012;14(2):160-166.

23 Chentli F, Azzoug S, Mahgoun S. Diabetes mellitus in elderly. Indian J Endocrinol Metabol. 2015;19(6):744. 